\title{
A Ciência e sua divulgação: implicações para o ensino de ciências
}

Rui Manoel de Bastos Vieira

\begin{abstract}
Resumo
Procuramos neste trabalho, a partir da análise de artigos científicos e de divulgação científica, estudar algumas características envolvidas no processo da passagem da esfera científica para a esfera midiática. O estudo foi estabelecido por meio dos parâmetros de gêneros do discurso desenvolvidos por Maingueneau, analista do discurso da escola francesa. Desta forma, estatutos para os parceiros, plano textual, finalidade e certo uso da língua foram os principais parâmetros utilizados com o objetivo de evidenciar elementos a serem considerados no processo de ensino-aprendizagem relacionados à estrutura das obras e ao contexto sociocultural em que estão inseridas.

Palavras-chave: gêneros do discurso, ensino de ciências, divulgação científica.
\end{abstract}

\section{Abstract}

Science and its Dissemination: implications for science education

Based on the analysis of scientific papers and popular science articles, we seek in this work to study some characteristics involved in the process of transposing from the scientific sphere to the media sphere. The study was established by the parameters of discourse genres developed by Maingueneau, a researcher of discourse analysis of the French school. Thus parameters as statutes for partners, text plan, purpose and use of certain language were the main parameters used in order to highlight the elements to be considered in the process of teaching and learning related to the structure of the works and the socioculturalcontext in which they operate. 
Keywords: discourse genres, science education, popularization of science.

\section{Introdução}

Provavelmente a interface mais próxima do grande público com a ciência é a divulgação científica que ocorre a partir dos mais diversos meios como museus, revistas, jornais, livros, programas televisivos, cinema, entre outros. Ribeiro e Kawamura (2009) destacam que reflexões sobre as potencialidades da divulgação científica e suas contribuições para o ensino têm sido foco de investigações na área de Ensino de Física. Dentre os papéis atribuídos e pesquisados da divulgação científica, destacam-se o desenvolvimento de habilidades de leitura, o contato com informações atualizadas sobre ciência e tecnologia, a formação de espírito crítico e reflexivo e a motivação.

Assim como Cunha e Giordan (2009), para que o uso da divulgação científica possa ser corretamente potencializado no âmbito educacional, acreditamos na necessidade do uso de teorias da análise do discurso para compreender a complexidade envolvida, principalmente, na mudança de um discurso que passa da esfera científica para esfera midiática. Desta forma, pretendemos neste trabalho estudar alguns elementos envolvidos neste processo que não podem ser negligenciados no contexto de ensino-aprendizagem.

\section{Alguns instrumentos de análise}

A partir da análise da estrutura mais formal de artigos científicos e de divulgação científica da mídia impressa, procuramos estabelecer as implicações determinadas por suas condições sociais de produção. Neste sentido, Grillo (2006), usando o referencial dos campos e esferas sociais da comunicação discursiva, derivado de Bakhtin e de Bordieu, estabelece alguns parâmetros contextuais. Segundo Grillo, o discurso da difusão científica sofre coerções de acordo com o campo em que ele se dá: científico (revistas científicas, congressos, etc.), educacional (aulas, apostilas, livros, seminários, etc.) e informação midiática (televisão, jornais, revistas de divulgação, reportagens, etc.). Há também uma distinção entrecruzada a essa: a comunicação primária realizada entre especialistas (de especialista para especialista) visando à divulgação dos trabalhos científicos, comunicação didática onde o destinatário é o aprendiz, e a comunicação secundária onde o destinatário do discurso é o não especialista, sem a intenção de incorporá-lo como futuro agente do campo. 
Para Bakhtin (2004), que examina a língua a partir do contexto social de sua produção, o discurso deve ser analisado de acordo com sua função na comunicação entre os falantes, que por sua vez devem ser considerados como portadores de pressupostos ideológicos e intencionalidades inerentes à sua prática social. Os enunciados dos discursos devem ser interpretados a partir deste contexto:

Toda enunciação, mesmo na forma imobilizada da escrita, é resposta a alguma coisa e é constituída como tal. Não passa de um elo em uma cadeia dos atos de fala. Toda inscrição prolonga aquelas que a precederam, trava uma polêmica com elas, conta as reações ativas da compreensão, antecipa-as. (Bakhtin, 2004, p. 98)

A enunciação linguística, ato de comunicação, tem um caráter social, e o produto dessa interação social é o enunciado. Neste sentido, os discursos são produzidos de acordo com as diferentes esferas e a competência linguística dos sujeitos está relacionada aos gêneros do discurso. Desta forma, os gêneros do discurso são diferentes formas de uso da linguagem que variam de acordo com as diferentes esferas.

A partir do conceito de gênero proposto por Bakhtin, Maingueneau (2006) considera que os gêneros textuais são atividades sociais que se submetem a critérios de êxito. $O$ autor estabelece parâmetros que permitem avaliar as principais características e as condições de êxito para os gêneros do discurso, segundo ele:

- Uma finalidade: o gênero do discurso visa provocar certo tipo de modificação da situação em que está inserido;

- Estatutos para os parceiros:a fala de um gênero do discurso parte de um indivíduo de um dado estatuto a outro indivíduo. O estatuto está relacionado a determinados direitos, deveres e saberes. Neste sentido, uma revista científica é direcionada a um leitor diferenciado do grande público.

- Circunstâncias adequadas:implica nos momento e lugar apropriados para seu êxito e, está relacionado ao tipo de produção, desta forma este contexto muda de texto oral para um escrito, por exemplo.

- Um modo de inscrição na temporalidade: é estabelecido a partir de dois subparâmetros: a periodicidade, relacionada aos intervalos do discurso, um pronunciamento de chefe do estado é diferente de um telejornal. A duração, um jornal pode ter ao menos duas: a leitura dos elementos em negrito, a leitura de todo texto.

- A continuidade:uma piada é contada de uma única vez enquanto uma novela possui várias etapas. 
- O tempo de validade:um jornal diário tem a duração de um dia, um texto sagrado é indefinidamente legível.

- Um suporte:o texto pode ser manuscrito, impresso, transmitido por ondas sonoras. A mudança do suporte material modifica o gênero, um debate político televisionado é distinto de um feito num auditório.

- Um plano textual: o gênero do discurso se associa a certa organização textual, aos modos de encadeamento de seus constituintes em diferentes níveis. Uma dissertação se diferencia de um resumo ou de carta comercial.

- Certo uso da língua: existe um repertório bem amplo de variedades linguísticas: diversidade de línguas, linguagem "popular", dialetos, variedades sociais, variedades profissionais (administrativo, científico, jornalístico ...) etc.

Desta forma, para caracterizar as coerções entre os diferentes campos e esferas, será empreendida, a seguir, a análise das produções textuais a partir destes parâmetros estabelecidos por Maingueneau.

\section{Análise das produções textuais}

Consideramos importante, em nosso trabalho, selecionar produções textuais que possuam as mesmas características em determinados parâmetros do gênero do discurso. Neste sentido os parâmetros circunstâncias adequadas, continuidade e suporte das obras analisadas são muito próximos, não comprometem a análise e, permitem que se extraiam parâmetros correlacionandoos. São produções textuais publicadas em tempos regulares.

Os artigos analisados foram selecionados a partir da sequência descrita a seguir. $\mathrm{Na}$ primeira etapa, foi pesquisado um artigo de divulgação científica (BBC, 2010), publicado em um jornal de grande circulação, que estabelecesse referência a um artigo publicado em uma reconhecida revista científica da comunidade científica internacional (Fossati et al, 2010). Após esta etapa, foi selecionado um trabalho em uma revista especializada em divulgação científica (Matson, 2010) com as mesmas referências estabelecidas pelo artigo de divulgação científica. No entanto este último trabalho fez referência a um artigo da revista Nature (LI et al, 2010), que também será utilizado em nossas análises. 
Para facilitar a escrita, neste trabalho iremos atribuir sigla $A C$ quando nos referirmos aos artigos científicos, DE para os artigos publicados em revistas especializadas em divulgação científica e DJ para os artigos presentes na seção Ciência de jornais de grande circulação ${ }^{1}$.

Ao analisar o plano textual dos diferentes artigos verificamos que todas as produções textuais são iniciadas por um título / subtítulo:

$A C_{1}:$ Metals in the exosphere of the highly irradiated planet WASP-12b

$A C_{2}:$ WASP-12b as a prolate, inflated and disrupting planetfrom tidal dissipation

DJ: Telescópio Hubble identifica estrela que está 'engolindo' planeta / Esta é a primeira vez que o fenômeno é constatado tão claramente, segundo os astrônomos

DE: O planeta que está sendo devorado por seu Sol / Observações do telescópio espacial Hubble parecem confirmar um futuro sombrio para planeta distante consumido por sua estrela-mãe

Notamos que as produções textuais $\mathrm{AC}_{1}$ e $\mathrm{AC}_{2}$ apresentam o título diretamente relacionado ao objeto de pesquisa realizada. No entanto, tanto DJ quanto DE enfocam diretamente os resultados das pesquisas, neste sentido o discurso empregado promove o "uma reversão da superestrutura do texto científico: as conclusões das pesquisas e as potenciais aplicações de seus resultados no cotidiano das pessoas ganham posição de destaque" (ZAMBONI, 1997). Este recurso, comumente utilizado por jornalistas, tem o intuito de criar uma situação inicial de suspense e interesse para promover a leitura dos demais parágrafos. $O$ trecho a seguir foi retirado do último parágrafo do texto $\mathrm{AC}_{1}$, somente nesta etapa do artigo é discutida diretamente a perda de massa de WASP-12b

This detailed information should allow us to determine whether these planets really are being photo-evaporated by their host stars, and, if so, to empirically deduce the mass loss rate. We encourage detailed element/ion-dependent modeling of the exosphere in the highly irradiated environment of WASP-12b and similar systems, and observations of other similar extrasolar planets. Thereis a rich new parameterspaceto explore.

A apresentação dos títulos / subtítulos é sucedida pela assinatura dos artigos. As produções AC se caracterizam por apresentarem a identificação dos autores na ordem de relevância e as

\footnotetext{
${ }^{1}$ Iremos nos referir aos artigos analisados a partir destas siglas. As respectivas referências estão na seção textos-fonte.
} 
respectivas instituições de pesquisa, "Shu-lin Li - Kavlilnstitute for AstronomyandAstrophysics; DepartmentofAstronomy, PekingUniversity, Beijing 100871, China" $\left(\mathrm{AC}_{2}\right)$. Portanto, nota-se a preocupação em estabelecer a autoria do trabalho além de indicar que os trabalhos publicados neste tipo de produção são restritos a uma comunidade de autores e que pertencem à reconhecidas instituições de pesquisa. Este aspecto é diferenciado na produção $D E$, assinada como "por John Matson" e na produção DJ, somente com o nome da instituição "BBC Brasil $B B C^{\prime \prime}$. Este parâmetro está relacionado ao item estatutos para os parceiros e indica, entre outros fatores, uma aproximação/identificação com o tipo de público ao qual é destinada cada produção.

Ao se analisar o desenvolvimento do corpo dos artigos, percebe-se em AC a subdivisão em tópicos bem definidos: introdução/resumo, que retrata em linhas gerais o objeto de pesquisa e os resultados; após foi estabelecida uma análise crítica para a metodologia, as hipóteses, a coleta e análise dos dados e os resultados obtidos; no final do artigo foram apresentadas todas as referências utilizadas em seu conteúdo. Desta forma, a metodologia adotada torna-se o elemento central do discurso, no entanto, é apresentada de forma linear e não são relatadas as etapas intermediárias de seu desenvolvimento, se caracterizando como um produto pronto e acabado.

Na análise de DJ e DE o corpo do artigo é um texto contínuo e as referências utilizadas são explicadas no próprio corpo. Ocorre a supervalorização dos resultados e praticamente a metodologia científica é extirpada do contexto. Vale ressaltar que em DE existe o comentário de que os resultados informados foram provenientes de modelos científicos "Medições da exosfera forneceram base para elaboração de um modelo teórico inicial sobre ..."ou então"Em estudo publicado ... foi elaborado outro modelo sobre ...".Zamboni (1997) alerta para esta característica dos trabalhos jornalísticos de divulgação científica, e destaca que a supressão ou simplificação da metodologia pode servir para diferenciar as produções de divulgação científica.

$\mathrm{Na}$ análise do parâmetro certo uso da língua, nota-se o uso da função de linguagem referencial (Jakobson, 2007) em todos os artigos. O discurso dos textos é caracterizado, linguisticamente, pela 3 a pessoa do verbo, demarcando a impessoalidade do autor, produzindo informação teórica e transmitindo conhecimentos acerca se seus objetos de estudo. Desta forma, preza-se pela transmissão legível e denotativa da mensagem que possui uma dimensão cognitiva, para a aquisição do conhecimento.

A linguagem utilizada nas produções $A C_{1}$ e $A C_{2}$ é marcada pela sua especificidade, expressões

como

"Threeindependentmethodsallrevealenhancedtransitdepthsattributabletoabsorptionbyresonanceli nesofmetals in theexosphereof WASP-12 $b^{\prime \prime}\left(A_{1}\right)$ necessitam do leitor um conhecimento de um campo específico da ciência para o entendimento, neste caso, a espectroscopia. Outra importante 
característica é o uso da linguagem matemática como importante elemento estruturante do discurso:

$A C_{2}$ : Gas slightly beyond the nozzle accelerates towards the star and attains a free-fall speed $v_{\mathrm{f}}$ and a local density $\rho\left(L_{1}\right) \approx \rho\left(Y_{\mathrm{R}}\right)\left(c_{\text {sound }} A_{\mathrm{R}} / v_{\mathrm{f}} \pi \Delta Y^{2}\right) \approx \rho\left(Y_{\mathrm{R}}\right)$. Because $\rho\left(L_{1}\right) \ll \rho\left(R_{\mathrm{p}}\right)$, this stream remains optically thin. It does not directly strike WASP-12 but forms a disk that is tidally truncated by WASP-12b at about $0.7 a=3 R_{\odot}$, where $R_{\odot}$ is the radius of the Sun.

As produções de divulgação científica são caracterizadas pelo uso de uma linguagem menos especializada e, portanto, mais acessível. No entanto a produção DE se diferencia da DJ por usar uma linguagem menos coloquial. A linguagem matemática é subtraída do contexto e são evitados os termos técnicos. Alguns autores como Cunha e Giordan (2009) destacam que o cientista aparece como um personagem para dar credibilidade ao texto e servindo como ferramenta de sustentação da fala do divulgador.

$D J$ : Os pesquisadores dizem que o planeta, chamado Wasp-12b, pode ainda existir por mais dez milhões de anos

DE: CaroleHaswell, astrofísica da OpenUniversity, na Inglaterra, e co-autora do novo estudo, admite que a taxa de perda de massa mude com o tempo

Em alguns casos ocorre uma (con)fusão entre estes personagens e os equipamentos/técnicas utilizados no trabalho científico e aparecem como vozes que falam dentro dos textos, como apresentado de DJ, "O Telescópio Espacial Hubble descobriu sinais de que uma estrela ...".

Os artigos de divulgação exploram a função de linguagem metalinguística (JAKOBSON, 2007) que denota a preocupação de autor em tornar o código acessível para o destinatário, desta forma, são utilizados a explicação do próprio código, comparações, analogias entre outros. Cunha e Giordan (2009), destacam que estes recursos são utilizados em função do texto de divulgação científica perseguir a sua auto-explicação.

\section{DJ: uma estrela semelhante ao nosso Sol}

DE: WASP 12 b e sua estrela-mãe, que estão a 870 anos-luz da Terra, foram batizados a partir da pesquisa do projeto SuperWasp (WideAngleSearch for Planets), que mantém telescópios nas Ilhas Canárias, Espanha e África do Sul.

$\mathrm{Na}$ análise do parâmetro estatuto entre os parceiros verifica-se que os artigos científicos e os de divulgação são destinados a públicos distintos e bem específicos. As produções $A_{1}$ e $A C_{2}$ são dirigidas para a comunidade científica, os saberes envolvidos são destinados a um grupo de pesquisadores. Outro fator que corrobora esta característica é o processo de submissão do artigo 
a um corpo editor composto por pesquisadores que avaliam se o trabalho contempla os requisitos pré-estabelecidos para sua publicação. As produções DJ e DE são dirigidas para o grande público, os saberes envolvidos contêm informações essenciais para o entendimento de um não especialista e, diferentemente da publicação científica, o artigo não passa pelas mesmas etapas de submissão. Todos estes fatores influenciam diretamente no parâmetro periodicidade das produções textuais analisadas.

No estudo do parâmetro finalidade conclui-se que as produções textuais são bem distintas. Os artigos AC caracterizam-se pela busca do reconhecimento pela comunidade científica, fato que também pode ser relacionado ao processo de submissão do artigo a um corpo editor, anteriormente descrito. Neste sentido, apesar dos pares autores/editores pertencerem à mesma esfera, nota-se que os autores se colocam numa posição inferior ao corpo editor, já que este último é diferenciado pela capacidade/direito de julgar o trabalho desenvolvido pelo primeiro. Outra finalidade a ser atribuída é a divulgação do trabalho desenvolvido e determinados saberes.

Nas produções DJ e DE, conclui-se que uma das principais finalidades está atrelada ao fator comercial e a apreensão do leitor, segundo Grillo, estes veículos de comunicação em massa "... sobrevivem da venda do seu produto ... a quase totalidade das receitas ... provém de verbas publicitárias, que são proporcionais à capacidade de captação do público-alvo e do prestígio do veículo". Também pode-se atribuir como outra finalidade a divulgação de determinados saberes produzidos pela ciência.

$\mathrm{Na}$ análise do parâmetro tempo de validade percebe-se nos artigos científicos uma predisposição para que os trabalhos permaneçam com um tempo maior quando comparados com os da divulgação científica que prezam pela atualidade dos fatos, das descobertas científicas. Neste sentido, conclui-se que prevalece uma perspectiva de que uma notícia anunciada há um mês num jornal diário, por exemplo, está antiga, mesmo que cientificamente seja o conhecimento de maior aceitação. No entanto destacamos que nas produções científicas, o tempo de validade é determinado pelo avanço das pesquisas da área estudada.

\section{Implicações para o ensino de Ciências}

Iniciamos este trabalho mencionando que parte das pesquisas em Ensino de Física tem como objeto de estudo o uso de matérias de divulgação científica no processo de ensinoaprendizagem e que as contribuições comumente estão relacionadas a aspectos como o desenvolvimento de habilidades de leitura, o contato com informações atualizadas sobre ciência e tecnologia, a formação de espírito crítico e reflexivo e a motivação. 
No entanto, Pechula (2002) destacaque as informações científicas veiculadas pelos meios de comunicação estariam sustentando o imaginário de que a ciência produz conhecimentos confiáveis, verdadeiros e dignos de aceitação. Neste mesmo sentido, Grillo (2006)ao considerar o parâmetro atualidade como uma coerção constitutiva do campo da informação midiática, destaca que na maioria dos casos:

A atualidade caracteriza o jornalismo como um relato dos acontecimentos contemporâneos à sua realização. Esse primado do presente acaba por produzir uma falta de perspectiva histórica dos fatos narrados, que são apresentados como um presente sem história. Em razão disso, prevalecem o relato de novas descobertas científicas, apresentadas sem o processo histórico e sem a tradição que permitiu o seu aparecimento, e a explicação de um procedimento científico, atrelado a algum fato da atualidade de outra área

Desta forma, ressaltamos que no contexto de ensino-aprendizagem em que é necessária a passagem do discurso da esfera científica para a esfera didática, é feito a partir de um processo muito complexo. Aqui podemos mencionar as ideias de Chevallard (1985) sobre esse processo, por ele denominado transposição didática, onde o saber sábio, aquele ao qual o discurso científico se refere, sofre um processo de seleção, transformação e adaptação às condições específicas da situação de ensino-aprendizagem, dando origem ao chamado saber a ensinar. Os agentes desse processo, que são os produtores do discurso, estão situados naquilo que Chevallarddenomina a noosfera, ou seja, os sujeitos envolvidos no processo educativo formal, que inclui os formuladores de políticas educacionais e de currículo, os professores, as editoras de livros didáticos e assim por diante.

Acreditamos que ao se acrescentar a esfera midiática nesse processo de transposição é necessário estabelecer alguns cuidados para não seja extirpada a compreensão da construção do conhecimento científico e da influência do contexto social e histórico nesse processo, já que a apresentação pura e simples das teorias ou "descobertas" científicas, sem qualquer contextualização social e histórica ou exploração da dimensão humana, acaba por transmitir uma visão pouco coerente da Ciência. Trabalhos como de Chalmers (1994) ainda ressaltam que não existe um consenso entre os filósofos da ciência acerca de sua epistemologia, no entanto acreditamos que não pode ser negligenciada no contexto educacional.

Neste sentido, a análise das obras estabelecidas neste trabalho, a partir dos parâmetros do gênero do discurso de Maingueneau, propiciou uma melhor compreensão de sua produção em face do contexto sociocultural em que estão inseridas além evidenciar parte das características deste contexto e da estrutura das obras. 


\section{Considerações finais}

A partir da análise das produções textuais,envolvidas no processo de passagem da esfera científica para a esfera midiática, procuramos identificar como os parâmetros dos gêneros do discurso estabelecidos por Maingueneauajudam na compreensão deste processo e que este não pode ser negligenciado no contexto educacional.

Neste sentido, destacamos que os discursos são sempre constituídos e dirigidos a um interlocutor. Assim, os discursos não existem por si só, mas enquanto ato da enunciação. Um texto de divulgação científica é constituído em função das expectativas do seu interlocutor, que neste caso é público leitor. No contexto educacional, o ato de enunciação, que for estabelecido a partir de um material de divulgação científica, necessariamente precisa ser feito em função da expectativa do estudante. Deste modo, nos parece fundamental analisar a mudança do interlocutor e, portanto pode-se concluir que nesta enunciação, fatores como políticas educacionais e de currículo e outras necessidades específicas do contexto escolar são necessárias.

\section{Referências}

\section{Textos-fonte}

\section{Artigos científicos:}

$\mathrm{AC}_{1}$ - Fossati, L. et al. Metals in the exosphere of the highly irradiated planet WASP-12b.The American AstronomicalSociety. The AstrophysicalJournalLetters714. 2010. Disponível em < http://iopscience.iop.org/2041-8205/714/2/L222/pdf/2041-8205_714_2_L222.pdf> Acesso em 01 de julho de 2010.

$A C_{2}-L i$, Shu-Lin et al. WASP-12b as a prolate, inflated and disrupting planet from tidal dissipation. Nature. Vol 463. Disponível em < http://www.nature.com/nature/journal/v463/n7284/pdf/nature08715.pdf> Acesso em 01 de julho de 2010.

\section{Artigos de divulgação científica:}

DE - Matson, J. O planeta que está sendo devorado por seu Sol. Scientific American Brasil. Disponível em <http://www2.uol.com.br/sciam/noticias/o_planeta_que_esta_sendo_devorado_por_seu_sol.ht $\mathrm{ml}>$ Acesso em 01 de julho de 2010.

DJ - BBC.Telescópio Hubble identifica estrela que está 'engolindo' planeta. BBC Brasil - BBC. Jornal Estado de São Paulo. Disponível em <http://www.estadao.com.br/noticias/geral,telescopio-hubble-identifica-estrela-que-estaengolindo-planeta,555924,0.htm> Acesso em 01 de julho de 2010. 


\section{Referências}

Bakhtin, M. Marxismo e filosofia da linguagem. São Paulo: Hucitec, 2004.

Chalmers, A. A Fabricação da Ciência. São Paulo - São Paulo. Fundação Editora da UNESP (FEU). 1994.

Chevallard, Y. La transposition didactique.Du savoir savant au savoir enseigné.Grenoble: La PenséeSauvage, 1985.

Cunha, M. B.; Giordan, M. A divulgação científica como um gênero de discurso: implicações na sala de aula. VII Enpec. Encontro Nacional de Pesquisa em Educação em Ciências. 2009.

Grillo, S. V. C. Divulgação científica na esfera midiática. Revista Intercâmbio, volume XV. São Paulo: LAEL/PUC-SP. 2006.

Jakobson, R.Linguística e Comunicação. São Paulo: Editora Pensamento-Cultrix. 2007.

Maingueneau, D. Discurso Literário. São Paulo: Editora Contexto. 2006.

Pechula, M. R. Os signos mítico-sagrados na divulgação científica dos meios de comunicação de massa. In: Atas do XXV Congresso Brasileiro de Ciências da Comunicação - INTERCOM. Salvador, BA. 2002.

Ribeiro, R. A.; Kawamura, M. R. D. Divulgação científica e ensino de física: intenções, funções e vertentes. EPEF. 2009.

Zamboni, L. M. S. Heterogeneidade e subjetividade no discurso da divulgação científica. 1997.

Tese (Doutorado) - Instituto de Estudos da Linguagem, Universidade Estadual de Campinas, Campinas. 1997.

Rui Manoel de Bastos Vieira. Universidade de São Paulo. Doutorando do Programa de PósGraduação Interunidades em Ensino de Ciências-USP. rui@usp.br 